\title{
Rheological Characterization of Powder Mixture Including a Space Holder and Its Application to Metal Injection Molding
}

\author{
Sang June Park ${ }^{1}$, Dongyeong Kim ${ }^{1}$, Dongguo Lin ${ }^{2}$, Seong Jin Park ${ }^{2}$ and Seokyoung Ahn ${ }^{1, *}$ \\ 1 School of Mechanical Engineering, Pusan National University, Busan 46241, Korea; \\ psj1511@hanmail.net (S.J.P.); dongyeong864@daum.net (D.K.) \\ 2 Department of Mechanical Engineering, Pohang University of Science and Technology, Pohang 37673, Korea; \\ dglin@postech.ac.kr (D.L.); sjpark87@postech.ac.kr (S.J.P.) \\ * Correspondence: sahn@pusan.ac.kr; Tel.: +82-51-510-2471
}

Academic Editor: Manoj Gupta

Received: 23 February 2017; Accepted: 28 March 2017; Published: 30 March 2017

\begin{abstract}
Metal injection molding (MIM) with the space holder technique is becoming one of the important fabrication methods for a net-shape production of micro-sized, porous, complex-shaped metal parts. For a successful injection molding step, rheological behavior of MIM feedstock is essential, which includes peculiar characteristics, such as a wall slip phenomenon. SUS 316L stainless steel powder, binder systems (paraffin wax, polypropylene, polyethylene, stearic acid) and three different sizes of spherically-shaped polymethyl methacrylate (PMMA) as a space-holder were used for this study. The porosity was controlled by varying the volume fraction of the space holder and a total of six different feedstocks were prepared. Rheological characteristics of the feedstock was investigated, especially on viscosities, including wall slip quantification by using a capillary rheometer. By thermogravimetric analysis, the debinding process for completely removing the space holder was proposed. Finally, the shrinkage and porosity of the tensile specimen produced through the sintering process were analyzed and the ultimate tensile strength was obtained.
\end{abstract}

Keywords: metal injection molding; rheological characterization; feedstock rheology; space holder; porous metal injection molding; slip phenomena; highly-filled suspension flow

\section{Introduction}

Porous metals have useful properties, such as relatively low density, high strength to weight ratio, large specific surface area, high gas and liquid permeability, high thermal conductivity, and excellent energy absorption capacity. Due to these advantages, there are a variety of manufacturing methods of making micro-porous metal foam shapes, as mentioned in Manonukul et al. [1]. Porous structures can be classified as open porosity and closed porosity structures. For examples, a closed porous structure can be used in applications that require lightweight structural elements with better acoustical and impact energy absorption. Open porous structures can also be used for high-performance applications, such as heat exchangers and heat sinks for thermal management, as well as medical implants, filters, and electrodes for biological and chemical reactions. The various beneficial characteristics of these materials and their manufacturing methods are listed by Heaney et al. [2]. One of the method is using a space holder material like $\mathrm{NaF}$ and $\mathrm{NaCl}$ in the hot isostatic pressing (HIP) process to achieve well-defined porosities and pore sizes. Although its mechanical properties are promising, the disadvantage of the method is that it is still a difficult shaping process after compaction and removal of the space holder. In order to overcome this drawback, MIM with the space holder technology has recently been proposed and applied by many researchers. MIM with the space holder technique can 
produce both open- and closed-cell complex shape metal parts. A typical MIM process is composed of four basic steps which are (1) mixing; (2) injection molding; (3) debinding; and (4) sintering processes [3]. For a successful injection molding step, analysis of the rheological properties of the feedstock is essential, and as a result, viscosity is one of the important parameters for process optimization. There are previous studies on MIM with the space-holder technique. Manonoukul et al. experimentally found a relationship between space holders and porosity of SUS 316L. They used polymethyl methacrylate (PMMA) for the space holder for its high rigidity, thermal resistance, non-reactiveness to metal powder, various size, and reasonable cost. They showed that PMMA did not blend with the binder system and found out that as the volume fraction of PMMA increased, the sintered density and mechanical properties decreased [1]. Several other studies cover various metals for MIM with the space holder technique, such as aluminum alloy [4], copper [5], stainless steel [6], and titanium alloy [7]. Köhl et al. studied the near-net-shape of NiTi shape memory alloys for use as a long-term implant by MIM with the space-holder technique. Their study showed that MIM is able to fabricate a porous NiTi implant in which strength is close to that of human bone. They investigated $\mathrm{NaCl}$, saccharose, and PMMA as candidate materials for the space holder and concluded that $\mathrm{NaCl}$ is the most promising due to its low C- and O- impurity contents for NiTi implant application [8]. Gülsoy and German studied influence of the space holder (PMMA)'s volume fractions on both injection molding and sintering processes of austenitic stainless steel [9]. The effect of space holder (PMMA)'s particle size and the volume fraction on dimensional tolerance was studied by Nishiyabu et al. [7,10]. The result showed PMMA is easily removed during thermal debinding and also porous part with $30 \%$ and $60 \%$ volume fractions of PMMA were successfully produced. In our study, PMMA was chosen as a material for space holders for the same reason as in the Manonukul's study: PMMA's melting temperature is higher than those of the binder materials in our study, and of the mixing and injection temperatures, so its shape can be kept before the debinding process. Since the existing research focuses mainly on the feasibility of MIM for producing porous metal parts, in this study, the influence of the size and the volume ratio of the space-holder to the rheological characterization of the MIM feedstock (including quantification of the wall slip) for optimization of the injection molding process was studied.

\section{Experimental Procedure}

\subsection{Materials}

The metal powder used in this study is SUS 316L stainless steel powder (Epson Atmix Co., Aomori, Japan). The properties of the powder and binders are summarized in Tables 1 and 2, and the binders are mainly of paraffin wax (PW), polypropylene (PP), polyethylene (PE), and stearic acid (SA). Polymethyl methacrylate (PMMA, Sunjin Beauty Science Co., Ansan, Korea) was used as a space holder and its characteristics are given in Table 3. Scanning electron microscope (Hitachi S3500N, Tokyo, Japan) photographs of powder, space holder, and mixtures are shown in Figures 1 and 2. Both SUS 316L powder and PMMA space holder are spherical and have excellent flowability and packing density.

Table 1. Particle size and density of metal powder (SUS 316L) used.

\begin{tabular}{ccc}
\hline SUS 316L & Particle Size $\left(\mathrm{D}_{50}\right)$ & Density $\left(\mathrm{g} / \mathrm{cm}^{3}\right)$ \\
\hline & $8.10 \mu \mathrm{m}$ & 7.95 \\
\hline
\end{tabular}

Table 2. Binder compositions and related properties.

\begin{tabular}{ccccc}
\hline Property & PW & PP & PE & SA \\
\hline Density $\left(\mathrm{g} / \mathrm{cm}^{3}\right)$ & 0.92 & 0.92 & 0.93 & 0.95 \\
Melting temperature $\left({ }^{\circ} \mathrm{C}\right)$ & 51 & 78 & 120 & 53 \\
Decomposition temperature $\left({ }^{\circ} \mathrm{C}\right)$ & $242 \sim 280$ & $464 \sim 481$ & $464 \sim 471$ & $246 \sim 275$ \\
\hline
\end{tabular}


Table 3. Powder space holder (PMMA) characteristics used for feedstock.

\begin{tabular}{cccc}
\hline PMMA & Particle Size $\left(\mathbf{D}_{50}\right)$ & Density $\left(\mathbf{g} / \mathbf{c m}^{\mathbf{3}}\right)$ & Melting Temperature $\left({ }^{\circ} \mathrm{C}\right)$ \\
\hline P1 & $20 \mu \mathrm{m}$ & 1.19 & 165 \\
P2 & $50 \mu \mathrm{m}$ & 1.19 & 165 \\
P3 & $80 \mu \mathrm{m}$ & 1.19 & 165 \\
\hline
\end{tabular}

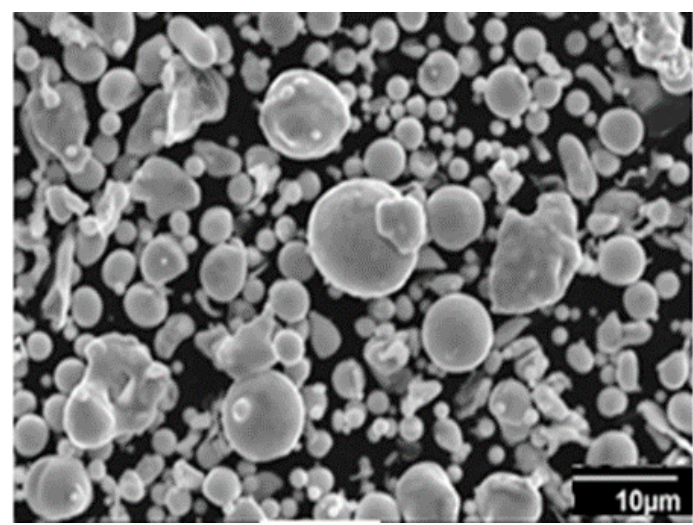

(a)

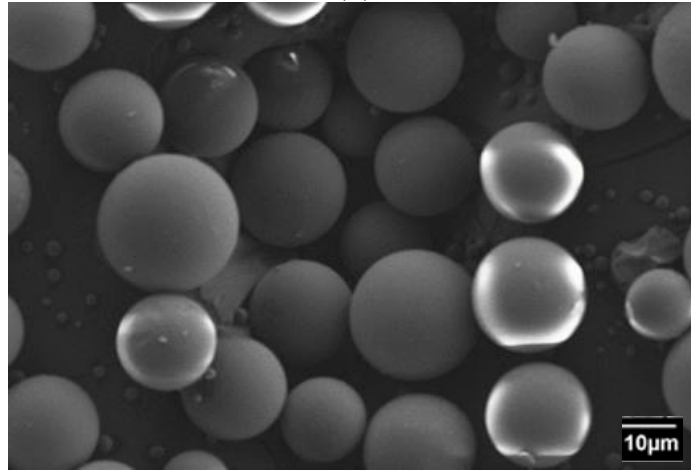

(c)

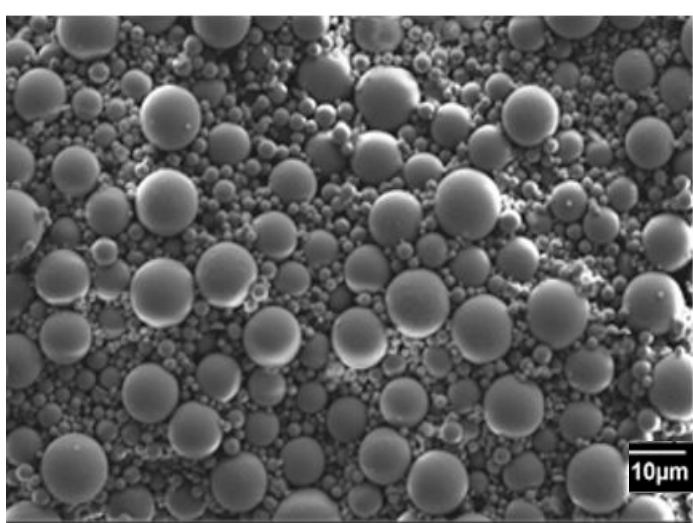

(b)

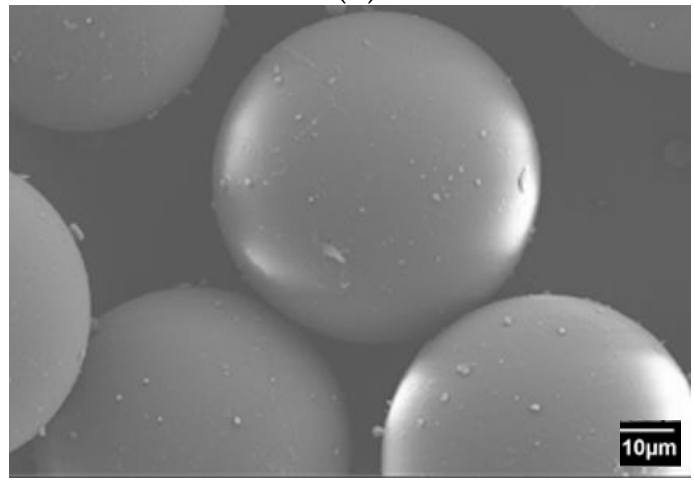

(d)

Figure 1. Scanning electron microscope photographs of (a) SUS 316L powder; (b) polymethyl methacrylate (PMMA) space holder: $20 \mu \mathrm{m}$; (c) PMMA space holder: $50 \mu \mathrm{m}$; and (d) PMMA space holder: $80 \mu \mathrm{m}$.

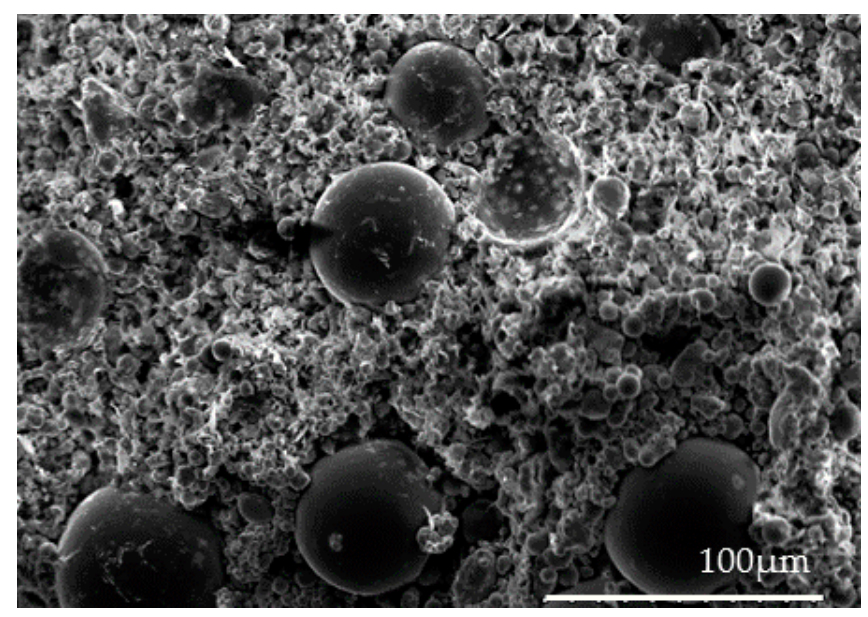

Figure 2. Scanning electron microscope photograph of powder, binder, and polymethyl methacrylate (PMMA) space holder $(50 \mu \mathrm{m})$ mixture. 


\subsection{Mixing of Powder-Binder-Space Holder Feedstock}

For a successful injection molding, homogenous mixing of powder and binder is essential. One significant factor affecting feedstock's homogeneity is solid loading percentage. Solid loading percentage refers to the volume ratio of powder to powder-binder mixture. When powder is packed tightly and binder fills all the voids between the particles, it is called the critical solid loading state [11]. A torque rheometer (Haake PolyLab QC, Thermo Scientific Inc., Waltham, MA, USA) was used to measure the critical solid loading point for the feedstock used in this study. The powders and binder were mixed at an operating temperature of $150{ }^{\circ} \mathrm{C}$ and a rotational speed of $150 \mathrm{rpm}$. When the rpm was stabilized, the powder was added in such a manner that $1 \mathrm{vol} \%$ of the powder was further added. Solid loadings were increased gradually from $55 \mathrm{vol} \%$ to $66 \mathrm{vol} \%$ until the torque reading became unstable. Figure $3 a$ shows the torque vs. time in minutes, where the torque increased with a solid loading and critical solid loading percent was found at $61 \mathrm{vol} \%$ for the feedstock by observing the slope change, as shown in Figure 3b. In general, the optimal solid loading is set 1\% to 3\% lower than the critical solid loading for process flexibility so optimal solid loading is set at $60 \mathrm{vol} \%$ in this study.

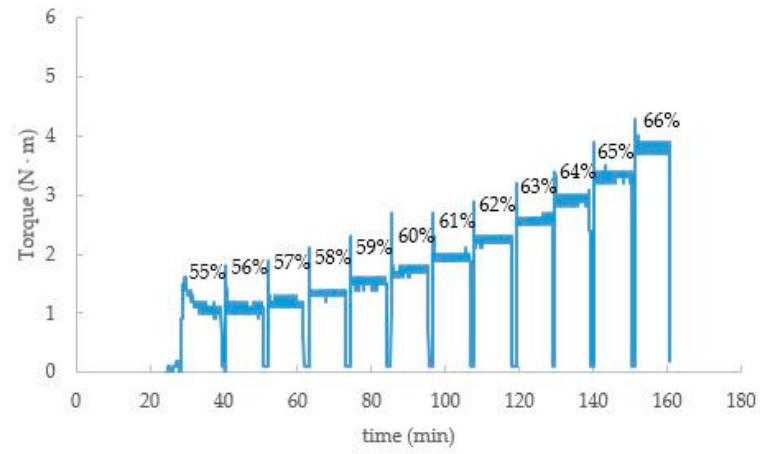

(a)

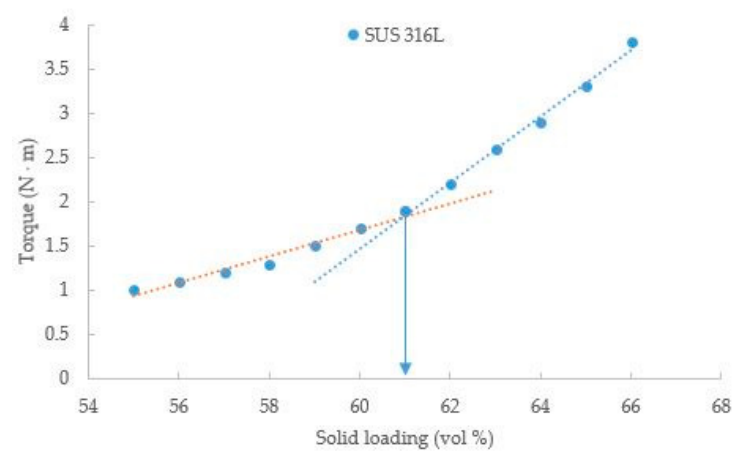

(b)

Figure 3. (a) Torque vs. time for finding critical solid loading, and (b) torque vs. solid loading using a torque rheometer.

For the study of rheological properties, a twin-screw extruder-type mixer (CetaTech Inc., Sacheon, Korea) was used for feedstock mixing and pelletization. A twin-screw extruder is the most widely used mixer in the MIM industry for feedstock production. The average mixing temperature was set at $150{ }^{\circ} \mathrm{C}$ below PMMA's melting temperature and the mixing speed was set at $30 \mathrm{rpm}$. To investigate the effect of size and volume fraction of PMMA on the rheological properties, six feedstocks were prepared and their composition is summarized in Tables 4 and 5. The premixed powder-binder-space holder mixture was mixed with the twin-screw extruder. To ensure homogeneity of the feedstock, the mixing step was repeated three times.

Table 4. Feedstocks with various polymethyl methacrylate (PMMA) space holder sizes (20, 50, $80 \mu \mathrm{m})$ and their volume percentages.

\begin{tabular}{cccc}
\hline Feedstock Numbering & SUS 316L (vol \%) & PMMA (vol \%) & Binder System (vol \%) \\
\hline F1 & 60 & 0 & 40 \\
F2 & 40 & $20(\mathrm{P} 1,20 \mu \mathrm{m})$ & 40 \\
F3 & 40 & $20(\mathrm{P} 2,50 \mu \mathrm{m})$ & 40 \\
F4 & 40 & $20(\mathrm{P} 3,80 \mu \mathrm{m})$ & 40 \\
\hline
\end{tabular}


Table 5. Feedstocks with various PMMA space holder vol \% with the fixed size (P2, $50 \mu \mathrm{m})$ and their volume percentages.

\begin{tabular}{cccc}
\hline Feedstock Numbering & SUS 316L (vol \%) & PMMA (vol \%) & Binder System (vol \%) \\
\hline F1 & 60 & 0 & 40 \\
F3 & 40 & 20 & 40 \\
F5 & 30 & 30 & 40 \\
F6 & 20 & 40 & 40 \\
\hline
\end{tabular}

\section{Rheological Characterization of the Feedstock}

\subsection{Viscosity Measurements Using Capillary Rheometer}

A uniform and complete filling of the mold during injection molding requires an understanding of the rheological properties of the viscous flow of the mixture, and viscosity is one of the most important required input parameters used in the CAE filling analysis of injection molding processes [11,12]. The viscosity of the feedstock in our study was measured by using a twin-bore barrel capillary rheometer (Rosand RH7, Malvern instruments Ltd., Malvern, UK). The measuring temperature was set at $150{ }^{\circ} \mathrm{C}$, the same as in the mixing process. While the feedstock passes through the capillary die, the ram position, pressure, shear rate, shear stress, viscosity, and ram speed are measured. Three different diameter capillary measurement bores $(\varphi 0.5 \times 8 \mathrm{~mm}, \varphi 1 \times 16 \mathrm{~mm}, \varphi 1.5 \times 24 \mathrm{~mm})$ with correction bores $(\varphi 0.5 \times 0.25 \mathrm{~mm}, \varphi 1 \times 0.25 \mathrm{~mm}, \varphi 1.5 \times 0.25 \mathrm{~mm})$ were used to quantify the wall slip phenomenon. A capillary rheometer is widely used due to its relatively high shear rate performance $(100-5000 \mathrm{~L} / \mathrm{s})$, which is close to the shear rate generated by the injection molding filling process. The result is viscosity vs. shear rate plots and will be discussed in the next section.

\subsection{Modified Cross-WLF Model}

One of the viscosity models representing the viscosity of the feedstock is the modified cross-WLF model as follows [13]:

$$
\eta=\frac{\eta_{0}}{1+\left(\frac{\eta_{0 \dot{\gamma}}}{\tau^{*}}\right)^{1-n}}
$$

where $\eta$ is viscosity of the feedstock, $\eta_{0}$ is zero shear viscosity, $\dot{\gamma}$ is shear rate, $n$ is power law index, and $\tau^{*}$ is critical stress level at the transition to shear thinning. The zero shear viscosity $\left(\eta_{0}\right)$ is given by the Equation (2):

$$
\eta_{0}=D_{1}\left[-\frac{A_{1}\left(T-T^{*}\right)}{A_{2}+T-T^{*}}\right], T^{*}=D_{2}+D_{3} p, A_{2}=\overline{A_{2}}+D_{3} p
$$

where $T$ is temperature $(\mathrm{K}), T^{*}$ is glass transition temperature, $p$ is pressure $(\mathrm{Pa})$ and $D_{1}, A_{1} \overline{A_{2}}$ and $D_{3}$ are data fitting coefficients. In this study, the modified cross-WLF model was used as a viscosity model to express viscosity of the feedstock. For MIM feedstocks, the modified cross-WLF model is generally more suitable than the power-law model.

\subsection{Results from Capillary Rheometer Experiements}

\subsubsection{Effect of PMMA Space Holder's Size}

To investigate the effect of size of PMMA space holder on viscosity, PMMA space holder diameters of $20 \mu \mathrm{m}, 50 \mu \mathrm{m}$, and $80 \mu \mathrm{m}$ were mixed with the powder and binder, respectively. SUS 316L:space holder:binder $=40: 20: 40 \mathrm{vol} \%$ was used for this study. Figure 4 a shows viscosity vs. shear rates for different size space holders (F1 has no PMMA, F2 has $20 \mu \mathrm{m}$ PMMA, F3 has $50 \mu \mathrm{m}$ PMMA, F4 has $80 \mu \mathrm{m}$ PMMA). The mixtures are showing shear-thinning fluid behavior. As can be seen in Figure 4, the viscosity of F2, F3, and F4 is lower than F1 because one third of the metal powder has been replaced 
by larger size PMMA space holders. It is also observed that the viscosity of the mixture decreases as the size of the space-holder increases and becomes less sensitive to the shear rate changes.

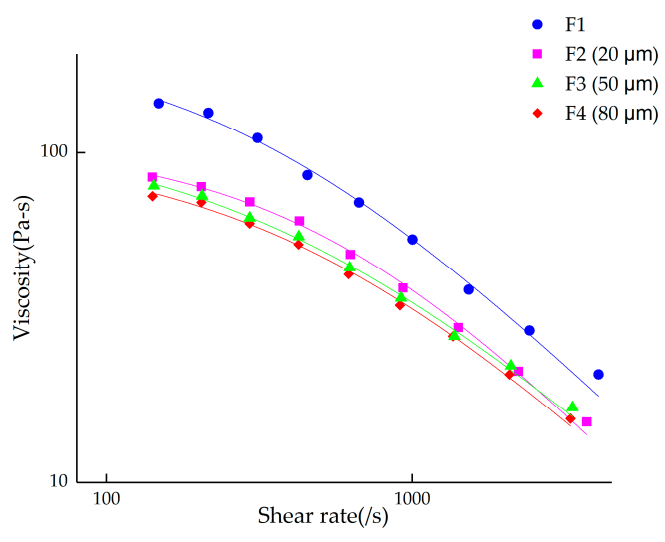

(a)

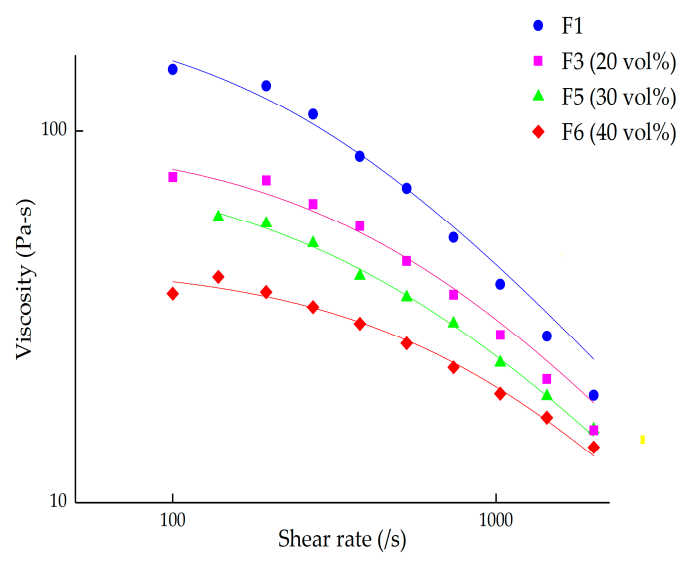

(b)

Figure 4. (a) Viscosity vs. shear rate results of F1, F2, F3, F4; and (b) viscosity vs. shear rate results of F1, F3, F5, F6.

\subsubsection{Effect of PMMA Space Holder's Volume Fraction}

In order to investigate the effect of volume ratio of PMMA space holder on viscosity, the diameter of PMMA space holder was fixed at $50 \mu \mathrm{m}$ and the ratio of space holder was changed to $20 \mathrm{vol} \%$, $30 \mathrm{vol} \%$, and $40 \mathrm{vol} \%$. In Figure $4 \mathrm{~b}$, the viscosity vs. shear rate for different PMMA volume fractions is shown. F1, F3, F5, and F6 are feedstocks with 0 vol \% PMMA, 20 vol \% PMMA, 30 vol \% PMMA, and $40 \mathrm{vol} \%$ PMMA space holder. In early trials, it was concluded that the part containing $50 \mathrm{vol} \%$ PMMA remained barely in shape during debinding and sintering were not suitable for the experiment because the shrinkage was too high, the same as in Manonukul's study [1]. It is observed that the viscosity of the mixture decreases as the volume fraction of the PMMA space holder increases and becomes less sensitive to the shear rate changes. From another point of view, a feedstock rich in metal powder is more viscous than a feedstock containing less. Comparing Figure $4 a, b$, it can be concluded that the variable more sensitive to viscosity change is the volume fraction of the space holder added to the mixture. This result is consistent with the previous rheological behavior study of a highly-filled suspension with varying particle size and volume fraction [13]. From this point of view, it can be concluded that the viscosity of the feedstock decreases as the particle size increases, even though two different sizes of particles (metal powder and space holder) are mixed as MIM feedstocks used in this study.

\subsubsection{Slip Phenomena of Powder-Binder-Space Holder Mixtures}

When a suspension fluid passes through a capillary die, slip may occur at the wall of the capillary where a solid-solid interface may occur. Without considering the slip phenomenon, the viscosity is eventually underestimated and a filling simulation based on viscosity without slip considerations results in misleading results. One of the models can describe the slip phenomenon as a slip velocity model, and the velocity profile of the fluid can change at the wall, as shown in Figure 5 [14]. 


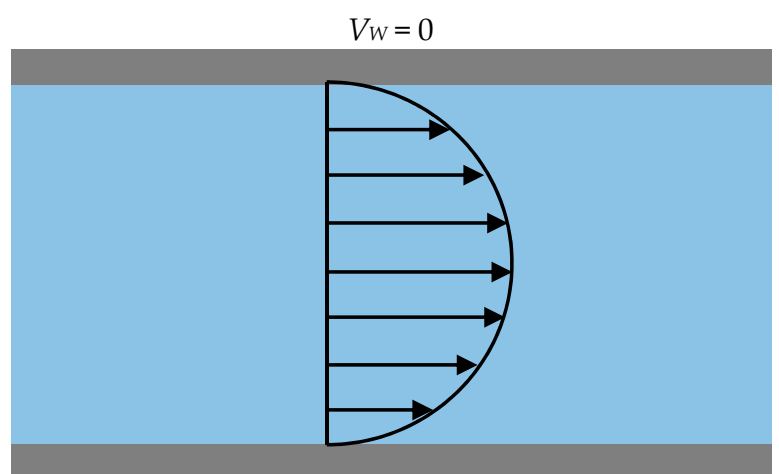

(a)

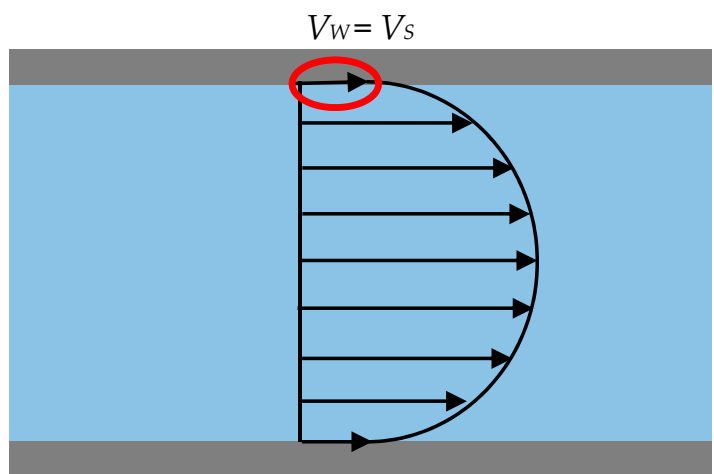

(b)

Figure 5. Velocity profiles of a suspension fluid at the wall: (a) no-slip; and (b) slip velocity $\left(V_{s}\right)$.

As shown in Figure 5, if there is a slip velocity $\left(V_{s}\right)$ at the wall, it can be measured using Mooney's method and related equations can be written as follows [15]:

$$
\frac{32 Q}{\pi D^{3}}=\frac{4}{\tau_{w}{ }^{3}} \int_{0}^{\tau_{w}} \tau^{2} \dot{\gamma} d \tau+\frac{8 V_{s}}{D}
$$

where $Q$ is the flow rate, $D$ is the diameter of the capillary rheometer, $\tau_{w}$ is the wall shear stress, $\tau$ is the shear stress, $\dot{\gamma}$ is the shear rate, and $V_{s}$ is the slip velocity. Fixing $\tau_{w}$ as a constant and taking the partial derivative of Equation (3) by 1/D results in the slip velocity formula as follows [13]:

$$
\left.8 V_{s}=\frac{\partial\left(\frac{32 Q}{\pi D^{3}}\right)}{\partial\left(\frac{1}{D}\right)}\right\rceil_{\tau_{\mathrm{w}}}
$$

$V_{S}$ can be calculated by Equation (4) by using various diameter capillary dies from the capillary rheometer experiment. In this study, $0.5 \mathrm{~mm}, 1 \mathrm{~mm}$, and $1.5 \mathrm{~mm}$ diameter capillary dies were used.

In Figure 6, the apparent shear rate vs. various 1/D at constant shear stress for F6 (SUS 316L:space holder:binder $=40: 20: 40 \mathrm{vol} \%$, PMMA particle size $=50 \mu \mathrm{m})$ is given. The slip velocity at the given shear stress is the slope of the regression lines drawn from the data points. In Figure 7, the slip velocity versus shear stress (for different sizes and volume fractions of PMMA space holder) are given in terms of a power law and the related coefficients are summarized in Table 6.

Table 6. Slip velocity as a function of a power law for each feedstock.

\begin{tabular}{cc}
\hline $\begin{array}{c}\text { Feedstock (Powder:Space Holder:Binder (vol \%), } \\
\text { Space Holder Size) }\end{array}$ & Slip Velocity (mm/s) \\
\hline F1 $(60: 40)$ & $V_{s}=5 \times 10^{-5} \tau_{w}{ }^{1.2263}$ \\
F2 $(40: 20: 40,20 \mu \mathrm{m})$ & $V_{s}=0.0064 \tau_{w}{ }^{0.8427}$ \\
F3 $(40: 20: 40,50 \mu \mathrm{m})$ & $V_{s}=0.0151 \tau_{w}{ }^{0.7692}$ \\
F4 $(40: 20: 40,80 \mu \mathrm{m})$ & $V_{s}=0.0068 \tau_{w}{ }^{0.8592}$ \\
F5 $(30: 30: 40,50 \mu \mathrm{m})$ & $V_{s}=0.0178 \tau_{w}{ }^{0.7672}$ \\
F6 $(20: 40: 40,50 \mu \mathrm{m})$ & $V_{s}=0.0191 \tau_{w}{ }^{0.85}$ \\
\hline
\end{tabular}

From Figures 6 and 7, it can be observed that the flow of powder-space holder-binder mixtures was strongly affected by slip at the wall. In Figure $7 \mathrm{a}$, with $20 \mathrm{vol} \%$ of powder being replaced by $20 \mathrm{vol} \%$ of PMMA (F2, F3, F4) result increase in slip velocity about 7 to 9 times. Replacing $40 \mathrm{vol} \%$ of powder to $40 \mathrm{vol} \%$ PMMA (F6) showed a slip velocity increase of about 9 to 13 times in Figure $7 \mathrm{~b}$. It can also be observed that the slip velocity increases with increasing size of the diameter of the PMMA space holder and volume fractions. 


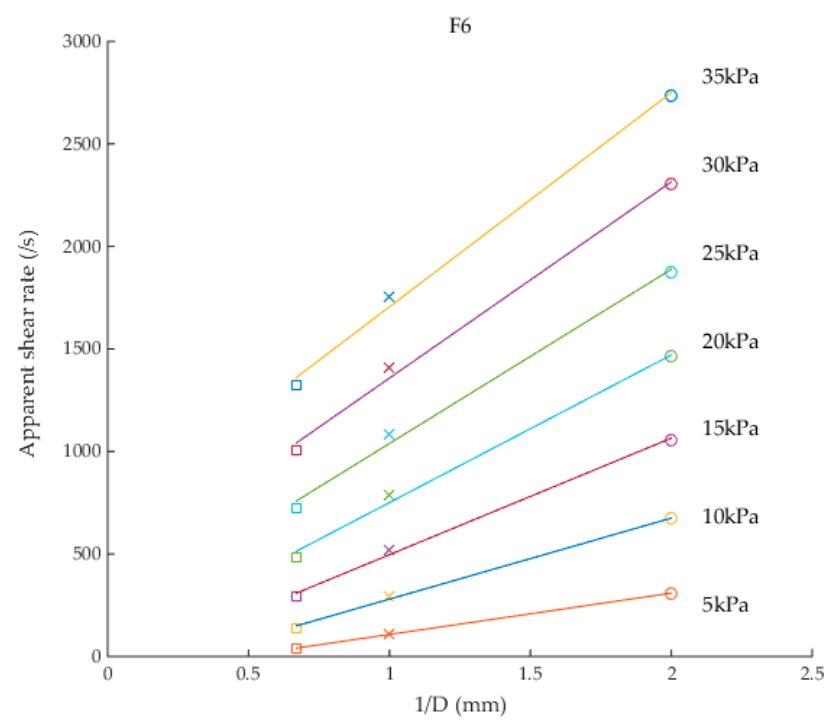

Figure 6. Apparent shear rate vs. 1/D for F6 which are SUS 316L:space holder:binder $=$ 20:40:40 vol \%, polymethyl methacrylate (PMMA) particle size $=50 \mu \mathrm{m}$ showing wall slip by using Mooney's method.

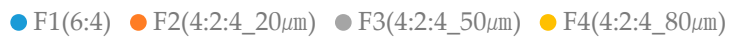

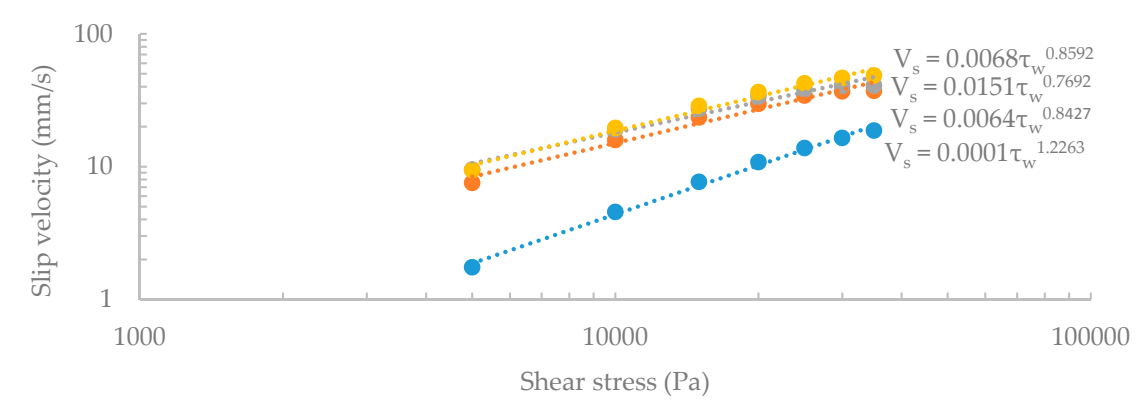

(a)

- F1(6:4) • F3(4:2:4) คF5(3:3:4) คF6(2:4:4)

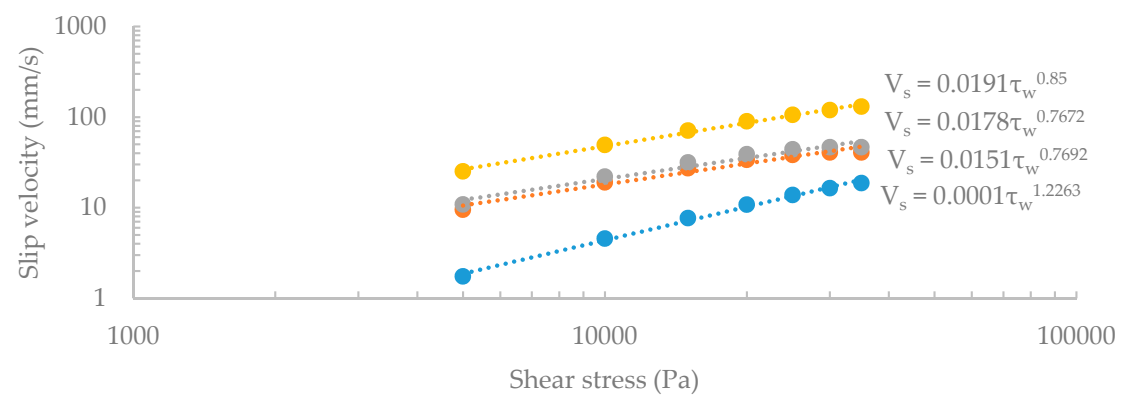

(b)

Figure 7. Slip velocity versus shear stress for different polymethyl methacrylate (PMMA) volume fractions (a) and sizes (b).

\section{Injection Molding, Debinding, and Sintering Processes}

\subsection{Injection Molding Process}

To produce porous metal parts for this study, tensile specimens were prepared by injection molding (Engel Victory 80, Engel, Schwertberg, Austria) with the feedstocks, which was based on 
the results from the previous section. To maximize the porosity, different sizes of the PMMA space holder were mixed together at wt. \% of $80(80 \mu \mathrm{m}): 19.5(50 \mu \mathrm{m}): 1.55(20 \mu \mathrm{m})$ and finally feedstocks with PMMA space holder vol \%, 0, 20, 30, and 40 were prepared. Tensile specimens were produced under the conditions given in Table 7.

Table 7. Injection molding parameters used for experimental study.

\begin{tabular}{cc}
\hline Parameter & Value \\
\hline Fill time & $1.4 \mathrm{~s}$ \\
Injection temperature & $150^{\circ} \mathrm{C}$ \\
Packing time & $4.0 \mathrm{~s}$ \\
Mold temperature & $40{ }^{\circ} \mathrm{C}$ \\
Cooling time & $10.0 \mathrm{~s}$ \\
Cycle time & $51.0 \mathrm{~s}$ \\
\hline
\end{tabular}

In order to prevent the space holder from melting and retaining the shape during the injection molding, the injection temperature was set at $150{ }^{\circ} \mathrm{C}$. Generally, PMMA decomposes above $200{ }^{\circ} \mathrm{C}$. These shape-retained space holders help to develop porous characteristics in the specimen. The tensile specimen has a rectangular cross-section with the width of $8 \mathrm{~mm}$ and the thickness of $4 \mathrm{~mm}$, a total length of $113 \mathrm{~mm}$, and a gauge length is $55 \mathrm{~mm}$. The cross-section of the green part was observed by SEM. It was confirmed from Figure 8 that the PMMA space holder is retaining its shape after the injection molding process (Figure 8).

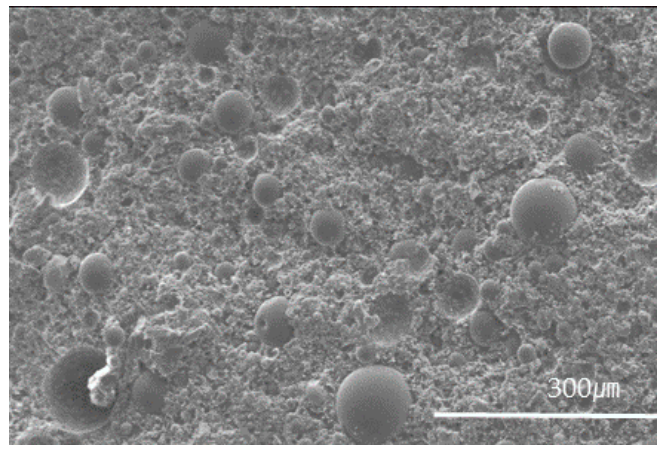

Figure 8. Scanning Electron Microscope (SEM) photograph of tensile specimen 'green' part.

\subsection{Debinding and Sintering Process}

The debinding process is generally a process of removing the binder from the green part. In our study, space holders have also been removed from the debinding process and are one of the key technologies in the overall process. PMMA also can be used as a binder, but since it is used as a space holder in this study, it should keep its shape in the binder during the mixing and injection molding process as mentioned earlier. In order to remove the binder and PMMA space holder, two sequential debinding processes were performed, solvent and thermal debinding. In this study, solvent debinding was performed using a hexane solution and the appropriate debinding time was determined by examining the weight reduction rate of the product after a certain period of time as follows [16]:

$$
\% W_{\text {loss }}=\left(W_{\text {initial }}-W_{\text {after }}\right) / W_{\text {initial }} \times 100
$$

$W_{\text {initial }}$ is the initial weight of the product, and $W_{\text {after }}$ is the weight after the solvent debinding process. The following graph shows the experimental results of the weight loss ratio of the part over time in hexane at a constant temperature of $50{ }^{\circ} \mathrm{C}$. The appropriate time for solvent debinding can be 
deduced from Figure 9 that the weight reduction rate during the solvent debinding increases for the first $8 \mathrm{~h}$, but then converges afterwards.

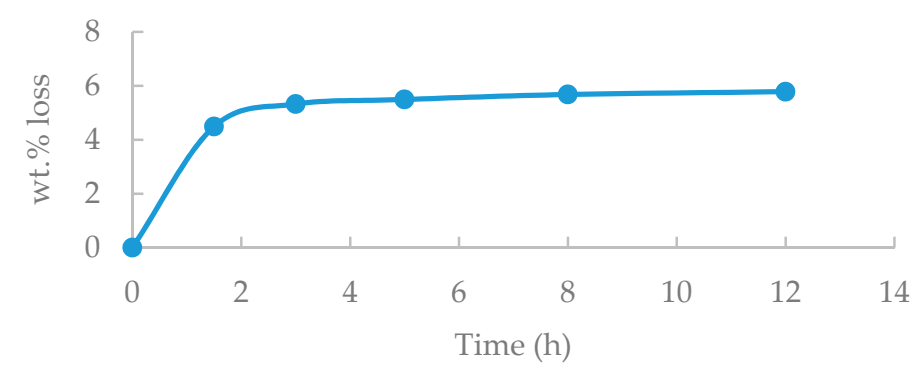

Figure 9. Weight loss changes with time for the solvent debinding.

Binders with low molecular weights, such as SA or PW, are weak to heat and may decompose and crack before sufficient channels to the surface are formed. Therefore, it is necessary to form a channel during the solvent debinding. $5.68 \mathrm{wt}$. \% of SA and PW (total $5.75 \mathrm{wt}$. \%) are removed after the solvent debinding process and the remaining SA and PW are removed completely at the thermal debinding stage as shown in Table 8 . The thermal debinding process conditions can be obtained from the thermal properties of the constituents of the binder and space holder. Therefore, mass change with time was observed using a thermogravimetric analyzer (Mettler Toledo TGA/DSC 1, Columbus, OH, USA) to obtain the decomposition temperature of the binder and PMMA. The TGA measurement was carried out at $30-600{ }^{\circ} \mathrm{C}$ at a heating rate of $10{ }^{\circ} \mathrm{C} / \mathrm{min}$ in a hydrogen atmosphere, much like the debinding process atmosphere (Figure 10).

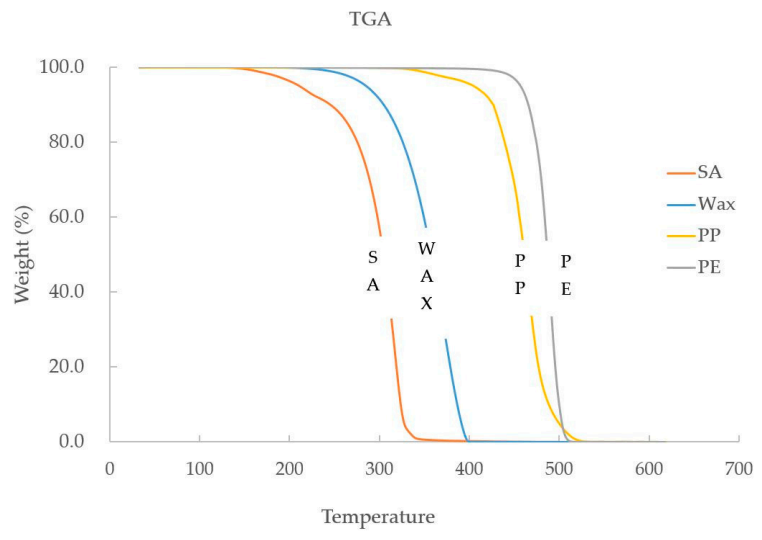

(a)

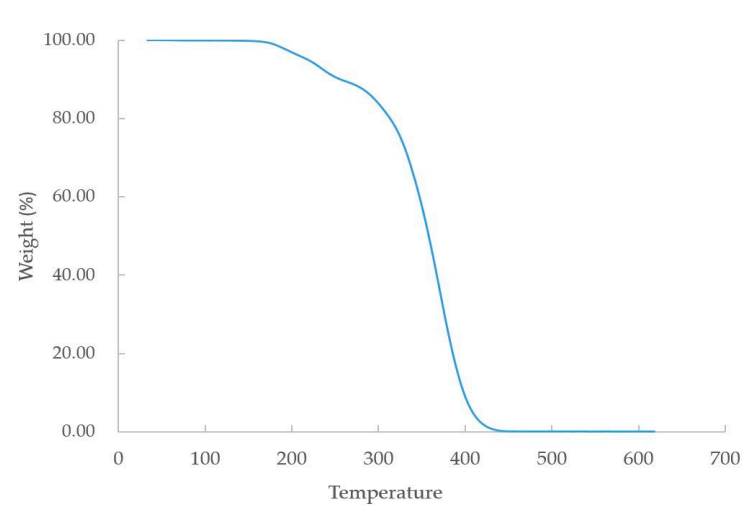

(b)

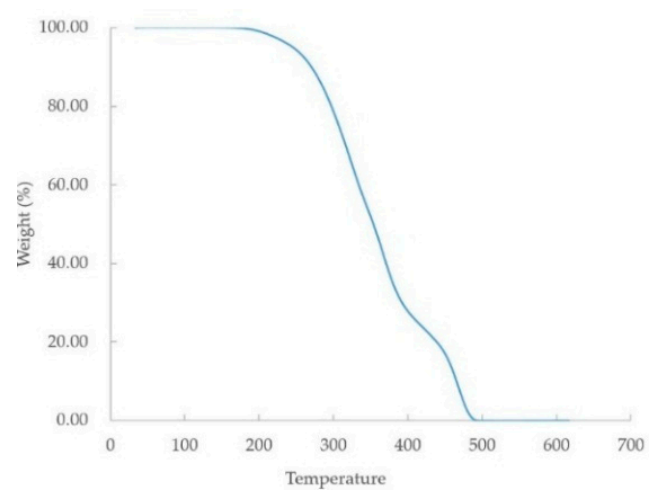

(c)

Figure 10. TGA results of (a) pure binder; (b) space holder; and (c) feedstock. 
In this study, a binder composed of PW, SA, PP, and PE was used. The TGA results show that SA and PW start to decompose between $180^{\circ} \mathrm{C}$ and $200{ }^{\circ} \mathrm{C}$, and decompose completely between $380^{\circ} \mathrm{C}$ and $400{ }^{\circ} \mathrm{C}$. Then, decomposition of PP and PE start at $380-400{ }^{\circ} \mathrm{C}$, where SA and PW were completely decomposed, and decomposed completely at about $500^{\circ} \mathrm{C}$. In the case of PMMA, decomposition starts at $180{ }^{\circ} \mathrm{C}$ to $200{ }^{\circ} \mathrm{C}$, and decomposes completely at $440{ }^{\circ} \mathrm{C}$, similar to decomposition start temperature of PW and SA. The TGA results of the feedstock show that the mass started to decrease at $180{ }^{\circ} \mathrm{C}$ to $200{ }^{\circ} \mathrm{C}$ as the result of the binder and PMMA. After that, SA, PW, and PMMA decreased rapidly at $200{ }^{\circ} \mathrm{C}$ and $400{ }^{\circ} \mathrm{C}$, respectively.

Debinding conditions were set through the decomposition temperature obtained from TGA results.

Stage 1. Decomposition of SA and PW (Up to $200{ }^{\circ} \mathrm{C}$ by $1{ }^{\circ} \mathrm{C} / \mathrm{min}$ for channel formation and then held for $1 \mathrm{~h}$ ).

Stage 2. Complete decomposition of SA and PW, and complete decomposition of space holder (up to $400{ }^{\circ} \mathrm{C}$ by $1{ }^{\circ} \mathrm{C} / \mathrm{min}$ then holding for $1 \mathrm{~h}$ ).

Stage 3. Complete decomposition of PP and PE (up to $500^{\circ} \mathrm{C}$ by $1{ }^{\circ} \mathrm{C} / \mathrm{min}$ and holding for $1 \mathrm{~h}$ ).

During the debinding process, it was maintained at $200{ }^{\circ} \mathrm{C}, 400{ }^{\circ} \mathrm{C}$, and $500{ }^{\circ} \mathrm{C}$ for $1 \mathrm{~h}$ so that sufficient channels for the binder's flows can be formed. In the binder removal process, hydrogen gas was continuously supplied to remove the gas generated by decomposition of the binder.

Moreover, in order to prevent the formation of oxides on the surface of the green part, the debinding process was carried out in a hydrogen atmosphere. Through the derived debinding profile, at the first attempt, a crack was found in the debinded body.

Considering that at the first debinding stage, the weight loss at $250-400{ }^{\circ} \mathrm{C}$ originated by not only SA and PW, but also the space holder. The mixture is composed of $20 \mathrm{vol} \%$ of the space holder, so more time is needed than a conventional debinding. The heating rate in the range of $200-400{ }^{\circ} \mathrm{C}$ was changed from $1{ }^{\circ} \mathrm{C} / \mathrm{min}$ to $0.5^{\circ} \mathrm{C} / \mathrm{min}$ so the space holder could be decomposed with a sufficient time. After this, the remaining binder was removed to prevent breakage in the brown part by heating up to $900{ }^{\circ} \mathrm{C}$ for pre-sintering. Finally, a brown part without cracks could be produced. The optimized debinding and pre-sintering processes are shown in Figure 11.

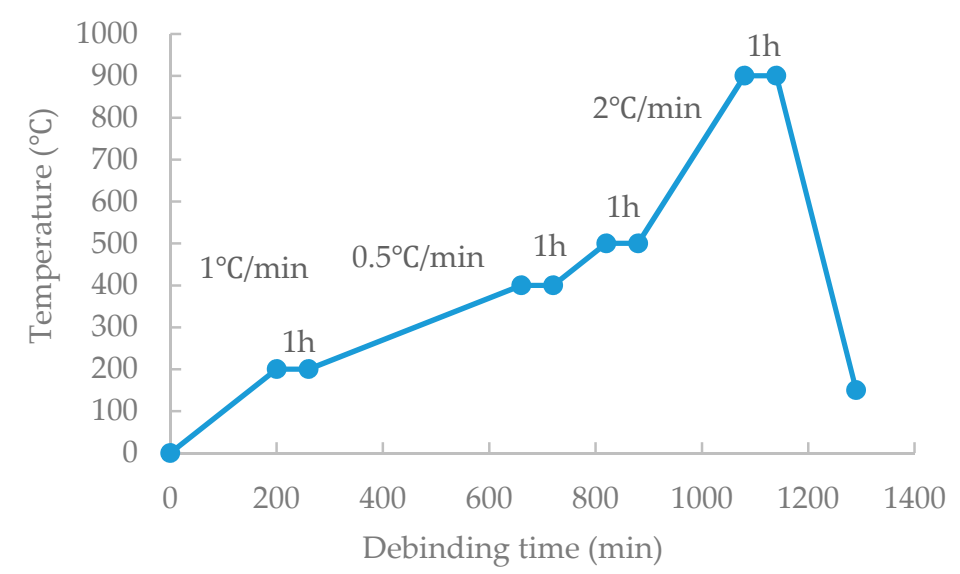

Figure 11. An optimized thermal debinding profile with pre-sintering process.

The mass change during solvent debinding and thermal debinding was calculated using the density and fraction of powder, binder, and the space holder by using the following equations [1]:

$$
\rho_{g}=\rho_{p} V_{f, p}+\rho_{b} V_{f, b}+\rho_{s} V_{f, s,} \quad V_{f, p}+V_{f, b}+V_{f, s}=1
$$


where, $\rho_{g}$ is the density of the green part and $\rho_{p}, \rho_{b}, \rho_{s}$ is the density of the powder, binder, and the space holder. $V_{f, p}, V_{f, b}, V_{f, s}$ is the volume fraction of powder, binder, and space holder. The sum of the volume fraction of powder, binder and space holder in the green part is constant.

In this study, the volume fraction of binder is constant at 0.4 , and the value of $\rho_{p}, \rho_{b}, \rho_{s}$ are $7.95 \mathrm{~g} / \mathrm{cm}^{3}, 0.9058 \mathrm{~g} / \mathrm{cm}^{3}$, and $1.19 \mathrm{~g} / \mathrm{cm}^{3}$. Using these values, the mass of the green part, $W_{g}$, and the volume of the green part, $V_{g}$, can be calculated. Then, the mass of binder, $W_{b}$, and space holder, $W_{s}$, can be calculated by the following equations and the values are listed in Table 8:

$$
\begin{gathered}
W_{g}=V_{g} \rho_{g} \\
W_{b}=V_{b} \rho_{b}=V_{f, b} V_{g} \rho_{b} \\
W_{s}=V_{s} \rho_{s}=V_{f, s} V_{g} \rho_{s}
\end{gathered}
$$

Table 8. Weight loss analysis of the tensile specimen during the debinding process.

\begin{tabular}{cccc}
\hline & Green Part Compositions & After Solvent Debinding & After Thermal Debinding \\
\hline Feedstock & 100 wt. $\%(19.19 \mathrm{~g})$ & $18.10 \mathrm{~g}$ & $16.14 \mathrm{~g}$ \\
SUS 316L & 84.12 wt. $\%(16.14 \mathrm{~g})$ & $16.14 \mathrm{~g}$ & $16.14 \mathrm{~g}$ \\
\hline PW & $5.51 \mathrm{wt.} \%$ & & \\
SA & 0.24 wt. $\%$ & & \\
PP & $2.40 \mathrm{wt.} \%$ & $-1.09 \mathrm{~g}(-5.68 \mathrm{wt} \%)$ & \\
PE & 1.44 wt. $\%$ & & \\
PMMA & 6.29 wt. $\%$ & & \\
\hline
\end{tabular}

After the solvent debinding process, the weight of the green part was reduced by $5.68 \mathrm{wt} \%$; mainly, the reduced weight was the PW and SA. Since the total wt. \% of PW and SA is $5.75 \mathrm{wt} . \%$, the remaining PW and SA will be further removed in the following thermal debinding process. After the thermal debinding process, the final brown part weighs $16.14 \mathrm{~g}$ so it can be assured that the remained binders are completely removed. The sintering process was performed under the following conditions as listed in Table 9. Since the binder and space holder were removed during the debinding process, the sintering process was carried out in the same way as the conventional SUS 316L sintering process.

Table 9. A sintering cycle used for the study.

\begin{tabular}{ccc}
\hline Time (min) & Temperature $\left({ }^{\circ} \mathbf{C}\right)$ & Heating Rate \\
\hline 0 & 20 & $5{ }^{\circ} \mathrm{C} / \mathrm{min}$. \\
270 & 1350 & holding time $80 \mathrm{~min}$. \\
350 & 1350 & cooling \\
590 & 150 &
\end{tabular}

In general, the residual binder can be removed by maintaining the temperature around $450{ }^{\circ} \mathrm{C}$ to $500^{\circ} \mathrm{C}$, but since the binder was removed through pre-sintering during the debinding process in this study, it was omitted (Figure 12).

The sintering process was performed in a hydrogen atmosphere to prevent the formation of oxides due to air, and the sintering was completed by maintaining the temperature at $1350{ }^{\circ} \mathrm{C}$ for $80 \mathrm{~min}$. As a result, the tensile specimen without deformation was obtained. 


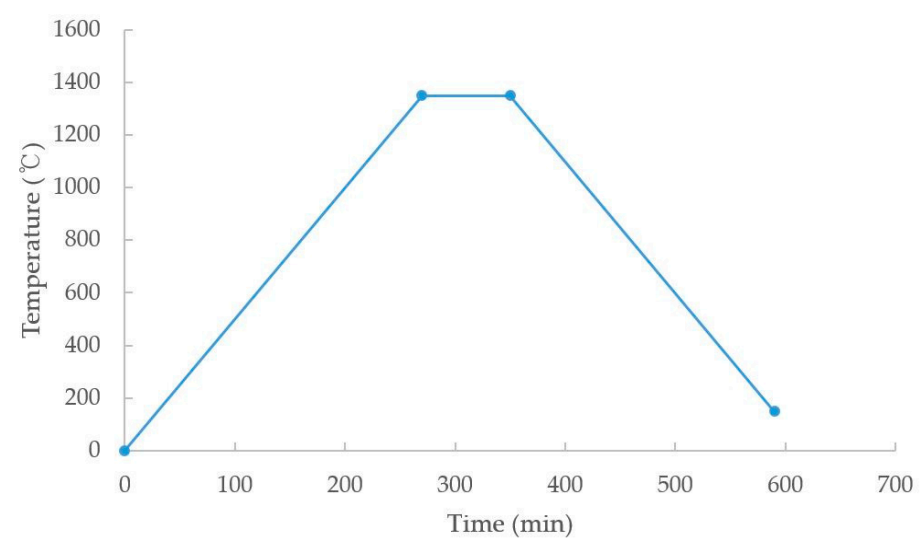

Figure 12. An optimized sintering profile for this study.

\section{Evaluation of the Tensile Specimens}

Tensile specimens with an inner porous structure were fabricated by a metal injection molding process with the space holder technique. Optimal microscope $(\mathrm{OM})$ equipment was used to observe the cross-sectional area of the specimens. OM observation confirmed the presence of spherical pores in the cross-section as shown in Figure 13.

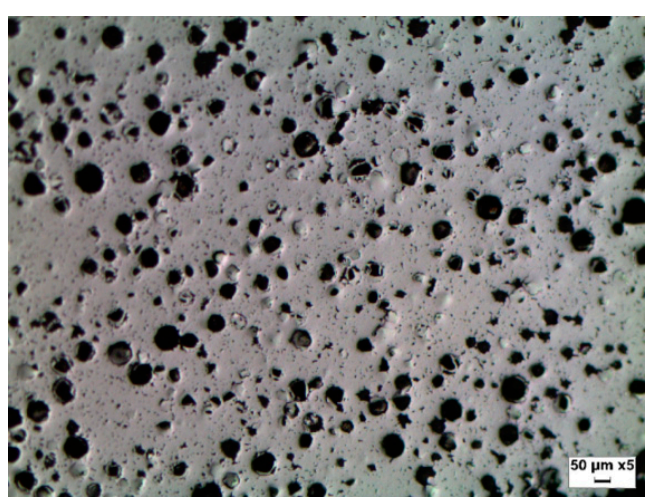

(a)

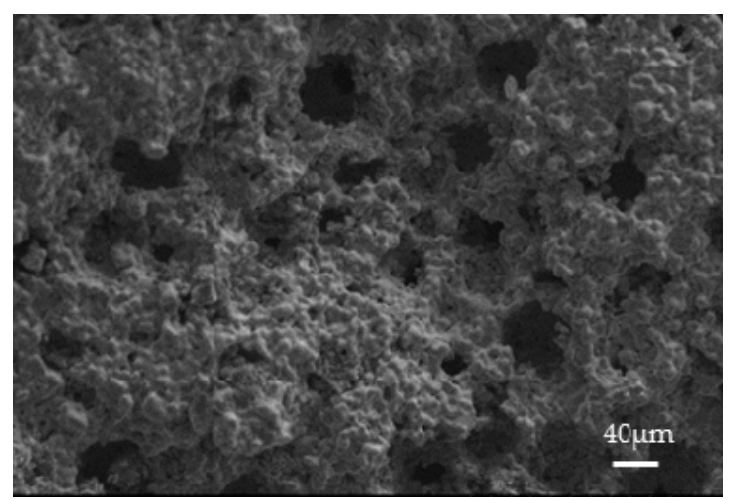

(b)

Figure 13. Optical photograph (a) and Scanning Electron Microscope (SEM) photograph (b) showing the cross-section of the sintered part with $30 \mathrm{vol} \%$ of polymethyl methacrylate (PMMA).

Tensile specimens with the space holder volume fraction from $0 \%$ to $40 \%$ were prepared by the method described above and the sintered parts are shown in Figure 14. Three tensile specimens were prepared from each volume fraction and the average values were used for their evaluations.

The porosity of the sintered parts is calculated by using the following porosity calculation equation. $V_{t}$ is the value for the apparent volume of the specimen and $V_{s}$ is the volume for the powder in the specimen, SUS 316L. The volume, $V_{t}$ was determined by Archimedes method and by micro CT scan (Nikon XT H 320, Tokyo, Japan). As the volume of the space holder increases, the weight of the sintered product becomes lighter, and the shrinkage ratio and the porosity increase.

$$
\text { Porosity }=\frac{V_{t}-V_{s}}{V_{t}} \times 100
$$

As shown in Figure 14, the leftmost part is the injection molded green part, and the volume fraction of the space holder increases toward the right. At 0, 20, and $30 \mathrm{vol} \%$, it shrinks linearly, but at $40 \mathrm{vol} \%$ shrinkage increases sharply. As shown in Figure 15a, the shrinkage rates of sintered parts 
with 0,20 , and $30 \mathrm{vol} \%$ space holders are $14 \%, 16.3 \%$, and $17.8 \%$, respectively. Additionally, as shown in Figure 15b, the porosity of sintered parts with 0, 20, and $30 \mathrm{vol} \%$ space holders are $14 \%, 34.6 \%$, and $47 \%$, respectively. However, in the case of the sintered part containing $40 \mathrm{vol} \%$ of the space holder, it was confirmed that the shrinkage was significantly increased to $24.61 \%$, but the porosity increasing rate decreased as listed in Table 10. Without the space holder, the shrinkage rate of the sintered part is $14 \%$, which means additional shrinkage was from the shrinkage of the porous structure. As more space holder was added, the shrinkage of the porous structure became significant because there was greater volume from the presence of space holder and less metal powder to support the structure [1]. To retain its shape of the sintered part, vol \% of the space holder above $40 \mathrm{vol} \%$ require special caution. The porosity measurement by micro CT scan showed the same tendency, and the volume measurement by micro CT scan is more reliable because of the characteristic of the Archimedes method that bubbles in pores cannot be sufficiently removed (Figure 16).

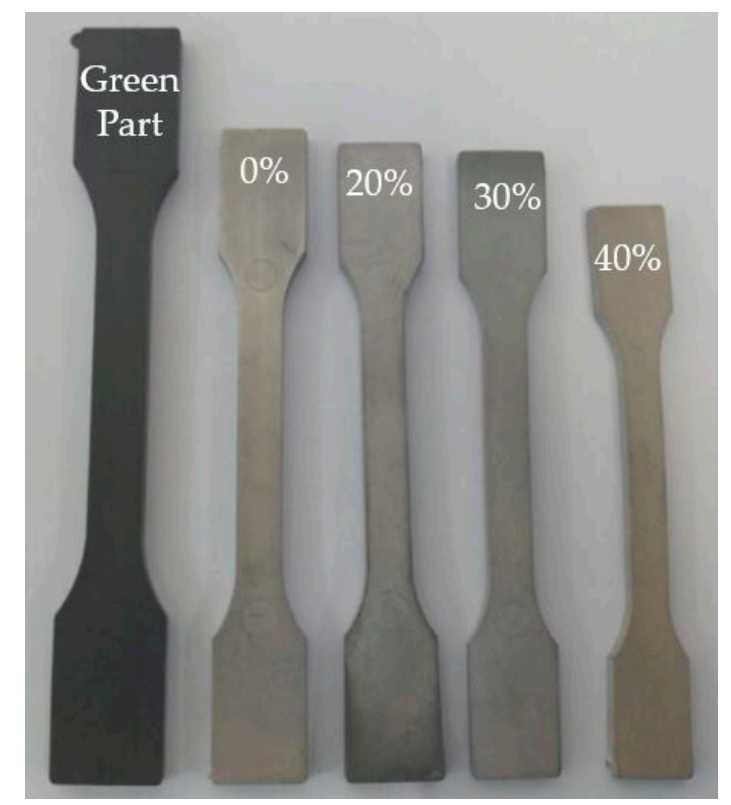

Figure 14. Sintered part and green part for different polymethyl methacrylate (PMMA) volumes.

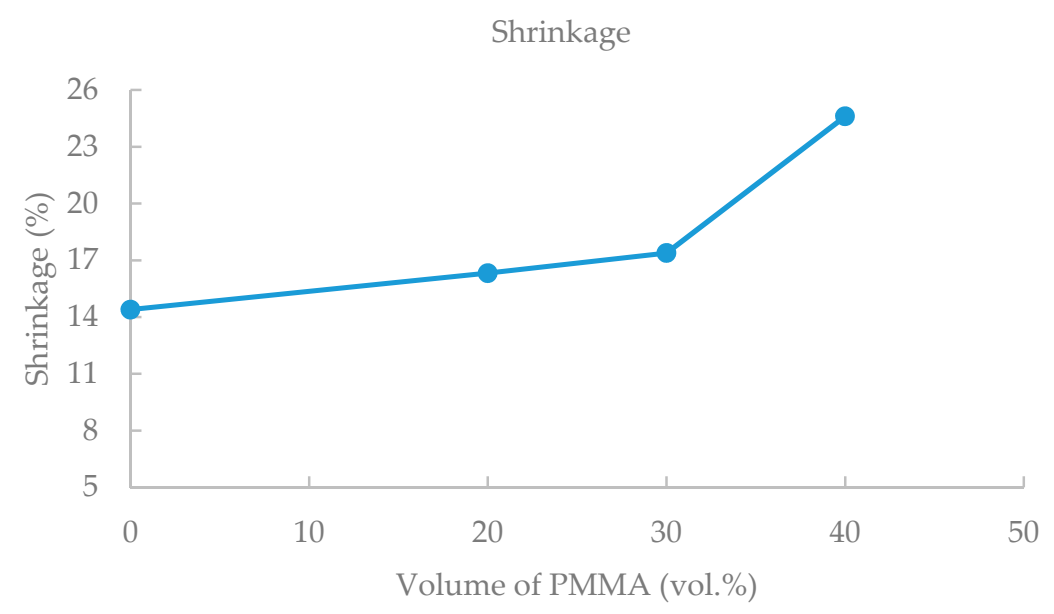

(a)

Figure 15. Cont. 


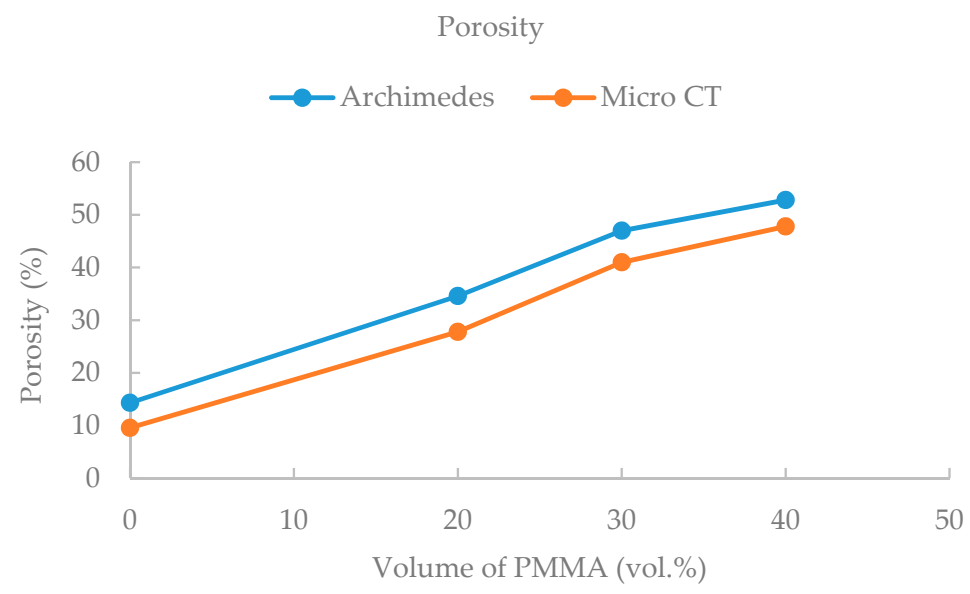

(b)

Figure 15. Comparison of sintered part with varied contents of polymethyl methacrylate (PMMA) shrinkage and porosity (a) shrinkage and (b) porosity effect of PMMA size.

Table 10. Comparison of the weight, shrinkage, and porosity of sintered parts produced at different PMMA volume ratios.

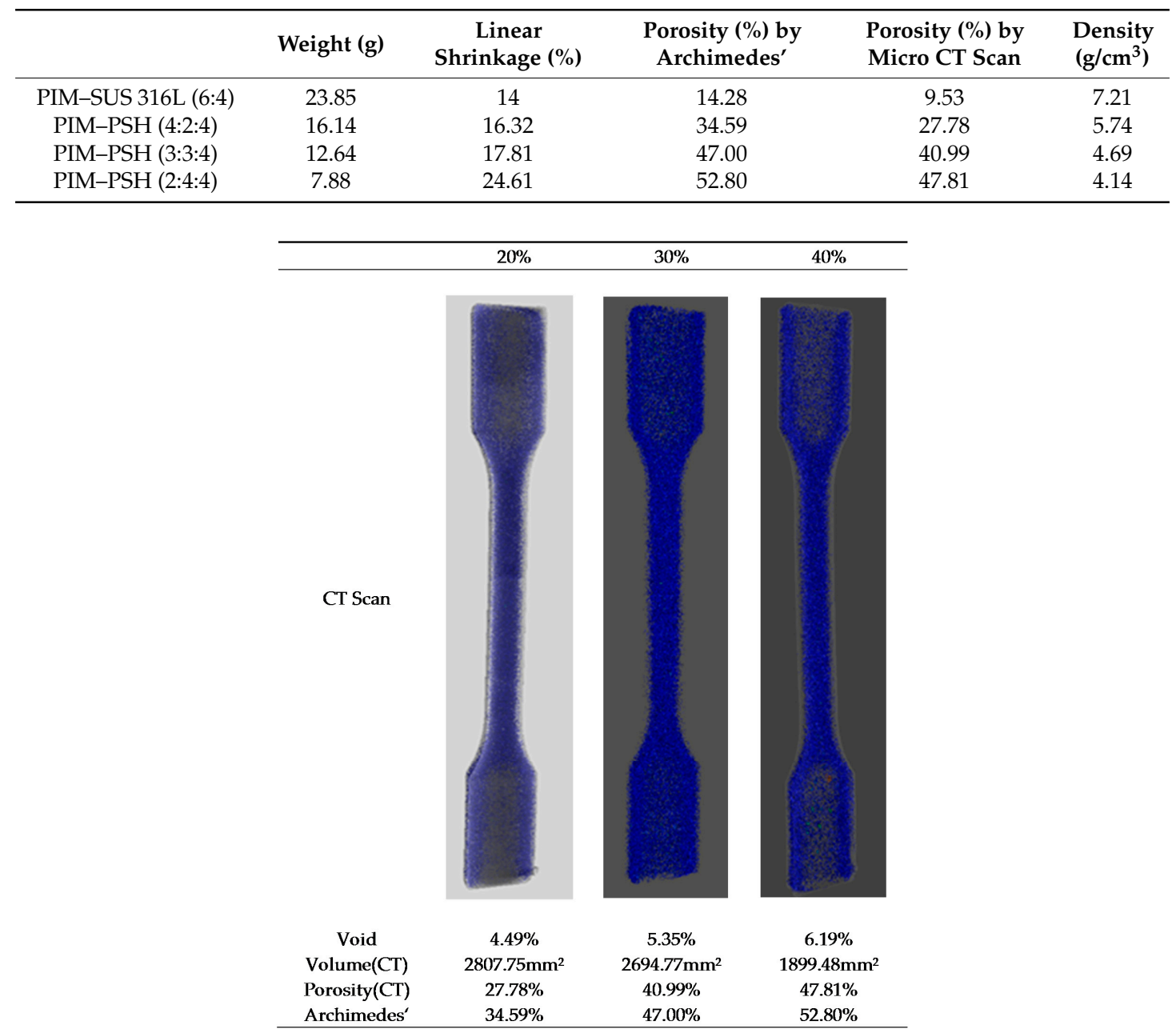

Figure 16. Micro CT scan of the tensile specimens and the porosity results for different polymethyl methacrylate (PMMA) space holder volume fractions. 
The specimens were evaluated for tensile strength according to MPIF standard 10. A holding force of 900 psi with $2 \mathrm{~mm} / \mathrm{min}$ speed was used for the measurement (MTS Landmark, Eden Prairie, MN, USA). The strength of four different volume fractions' specimens was measured. The tensile strength of the specimen tends to decrease as the PMMA fraction increases as shown in Figure 17.

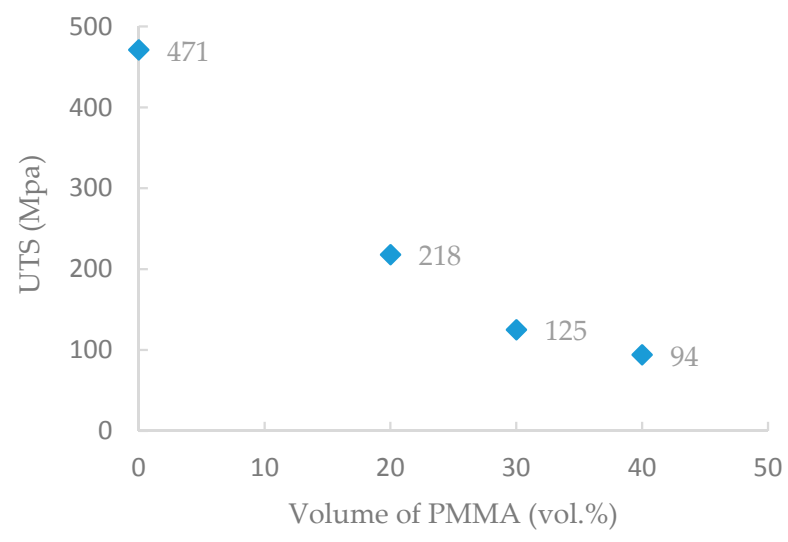

Figure 17. Tensile strength of sintered part with varied contents of polymethyl methacrylate (PMMA) space holder.

\section{Conclusions}

The purpose of this study was to investigate (1) how the rheological properties of PMMA space holders vary according to the size and volume fraction of PMMA; (2) how to completely remove space holders during debinding while retaining its porous characteristics; and (3) the relationship between PMMA space holder volume fraction with shrinkage, porosity, and mechanical properties of the final sintered products. In this study, we investigated the feedstock's rheological characteristics by capillary rheometry. Slip phenomena of the feedstock was quantified as a function of PMMA space holder size and volume fractions. To find out the critical solid loading, torque rheometer was used. The thermal properties of the feedstock were obtained using a thermogravimetric analyzer (TGA) to obtain the appropriate debinding process conditions. The tensile specimens were prepared using a feedstock having fraction of different space holders. The shrinkage, porosity, and tensile strength of the sintered parts were compared according to the volume fractions of space holder. The results can be summarized as,

- Effect of the PMMA space holder's size and volume fraction

It was observed that the viscosity of the feedstock decreases as the size of the space holder increases, and the volume fraction of the space holder also exhibits the same tendency. The results matches with rheological characteristics of a highly-filled suspension.

- Wall slip phenomenon

The flow of powder-space holder-binder mixtures was strongly affected by slip at the wall. The slip velocity increased with size of the diameter of PMMA space holder and volume fractions. The slip velocity of the feedstock was quantified as a power law of wall shear stress.

- Debinding process optimization

The appropriate solvent debinding process time was determined through the mass reduction rate according to the time of the green part immersing in the hexane solution. Solvent debinding was performed at $50{ }^{\circ} \mathrm{C}$ for $8 \mathrm{~h}$ and it showed that most SA and PW were removed. After that the residual binder and space holder could be removed through the thermal debinding process conditions obtained by TGA analysis. It was necessary to lower the heating rate for the thermal debinding due to the presence of the space holder. 


\section{- Evaluation of the sintered tensile specimen}

Observing the cross-section of the sintered product, it was found that spherical pores are uniformly formed. Through the calculation of porosity using Archimedes' law and micro CT scan analysis, the porosity and shrinkage rate were measured. When $40 \mathrm{vol} \%$ of the space holder was added, the shrinkage was $24.61 \%$ which was significantly higher than $17.81 \%$ shrinkage of the sintered part containing $30 \mathrm{vol} \%$ or less of the space holder. As a result of the tensile test, it was found that the strength decreased from $471 \mathrm{MPa}(0 \mathrm{vol} \%)$ to $218 \mathrm{MPa}(20 \mathrm{vol} \%), 125 \mathrm{MPa}(30 \mathrm{vol} \%)$, and $94 \mathrm{MPa}$ (40 vol \%) as the amount of space holder increased.

Acknowledgments: This work was supported by a two-year research grant of Pusan National University.

Author Contributions: Sang June Park and Dongyeong Kim designed and performed the experiments, Dungguo Lin and Seong Jin Park contributed in TGA analysis for debinding. Seokyoung Ahn wrote the paper.

Conflicts of Interest: The authors declare no conflict of interest.

\section{References}

1. Manonukul, A.; Mueya, N.; Leaux, F.; Amaranan, S. Effects of replacing metal powder space holder on metal foam produced by metal injection molding. J. Mater. Proc. Technol. 2010, 210, 529-535. [CrossRef]

2. Heaney, D.F.; Gurosik, J.D.; Binet, C. Isotropic forming of porous structures via metal injection molding. J. Mater. Sci. 2005, 40, 973-981. [CrossRef]

3. German, R.M. Powder Injection Molding; Cambridge University Press: Cambridge, UK, 1990.

4. Nishiyabu, K.; Matsuzaki, S.; Ishida, M.; Tanaka, S.; Nagai, H. Development of porous aluminum by metal injection moulding. Mater. Forum 2004, 28, 376-382.

5. Zhang, E.; Wang, B. On the compressive behaviour of sintered porous coppers with low to medium porosities. Part I. Experimental study. Int. J. Mech. Sci. 2005, 47, 744-756. [CrossRef]

6. Nishiyabu, K.; Matsuzaki, S.; Tanaka, S. Net-shape manufacturing of micro porous metal components by powder injection molding. Mater. Sci. Forum 2007, 534-536, 981-984. [CrossRef]

7. Dunand, D.C. Processing of titanium foams. Adv. Eng. Mater. 2004, 6, 369-376. [CrossRef]

8. Köhl, M.; Habijan, T.; Bram, M.; Buchkremer, H.P.; Stöver, D.; Köller, M. Powder metallurgical near-net-shape fabrication of porous NiTi shape memory alloys for use as long-term implants by the combination of the metal injection molding process with space-holder technique. Adv. Eng. Mater. 2009, 11, 959-968. [CrossRef]

9. Gülsoy, H.Ö.; German, R.M. Production of micro-porous austenitic stainless steel by powder injection molding. Scr. Mater. 2008, 58, 295-298. [CrossRef]

10. Nishiyabu, K. Powder space holder metal injection molding (PHS-MIM) of micro-porous metals. In Handbook of Metal Injection Molding; Woodhead Publishing Limited: Cambridge, UK, 2012.

11. Park, S.J.; Wu, Y.; Heaney, D.F.; Zou, X.; Gai, G.; German, R.M. Rheological and thermal debinding behaviors in titanium powder injection molding. Miner. Met. Mater. Soc. ASM Int. 2008, 40, 215-222. [CrossRef]

12. Bigg, D.M.; Barry, R.G. Progress in 56th Society of Plastic Engineers-Annual Technical Conference; Carlstedt, U., Stanaszek, M.J., Eds.; CRC Press: Brookfield, CT, USA, 1998; pp. 997-1000.

13. Ahn, S.Y.; Kwon, T.H. Slip characterization of powder/binder mixtures and its significance in the filling process analysis of powder injection molding. Powder Technol. 1995, 85, 45-55.

14. Soltani, F.; Yilmazer, U. Slip velocity and slip layer thickness in flow of concentrated suspensions. J. Appl. Polym. Sci. 1998, 70, 515-522. [CrossRef]

15. Mooney, M. Explicit Formulas for Slip and Fluidity. J. Rheol. 1931, 2, 210. [CrossRef]

16. Ibrahim, M.H.I.; Amin, A.M.; Wahab, M.S.; Asmawi, R.; Mustafa, N. Solvent debinding variables on leaching Fat, Oil and Grease (FOG) derivatives of green part stainless steel SS316L metal injection moulding. In Proceedings of the International Symposium on Technology Management and Emerging Technologies (ISTMET), Kedah, Malaysia, 25-27 August 2015; pp. 273-278.

(C) 2017 by the authors. Licensee MDPI, Basel, Switzerland. This article is an open access article distributed under the terms and conditions of the Creative Commons Attribution (CC BY) license (http://creativecommons.org/licenses/by/4.0/). 